\title{
UTILIZAÇÃO DA CASCA DE CAFÉ COM CARVÃO VEGETAL COMO MATERIAL REDUTOR E ENERGÉTICO NA INJEÇÃO DE MATERIAL PULVERIZADO NAS VENTANEIRAS DOS ALTOS-FORNOS*
}

\author{
Ricardo dos Santos Oliveira ${ }^{1}$ \\ Carlos Frederico Campos de Assis $^{2}$ \\ Paulo Santos Assis ${ }^{3}$ \\ Bruno Sardenberg de Castro Lima ${ }^{1}$ \\ Marina do Carmo Carias ${ }^{4}$
}

\section{Resumo}

Este trabalho foi realizado a partir da identificação do problema da alta geração de resíduos cafeeiros e de emissão de gases poluentes pelas indústrias siderúrgicas. Ao analisar as emissões nacionais de sistemas de energia, observou-se que o segmento da indústria de aço tem uma importante participação devido ao alto consumo de carvão metalúrgico e coque no balanço energético. O projeto teve como objetivo utilizar duas biomassas, a casca de café e o carvão vegetal, como uma fonte de energia no processo de redução do minério de ferro, através da injeção de finos pulverizados pelas ventaneiras de altos-fornos. O cafeeiro e a planta de eucalipto são fontes renováveis, ao contrário do carvão mineral, e através da fotossíntese capturam o gás $\mathrm{CO}_{2}$ da atmosfera, reduzindo parte da poluição causada pelos altos-fornos à coque. Para simular a possibilidade de injetar as biomassas estudadas, um simulador de injeção de materiais pulverizados foi utilizado. Foram utilizadas, também, técnicas para caracterizar os materiais, como classificação granulométrica, combustão, calorimetria, análise de gás, superfície específica, microscópica e química. Através do estudo, esta pesquisa mostra que a casca de café pode ser injetada em altos-fornos substituindo parcialmente a moinha de carvão vegetal.

Palavras-chave: Alto-forno; Injeção; Casca de café; Carvão vegetal.

\section{UTILIZATION OF COFFEE HUSK AND CHARCOAL AS REDUCING AND ENERGETIC MATERIAL IN INJECTION OF PULVERIZED MATERIAL IN TUYERES FOR BLAST FURNACE}

\section{Abstract}

This present paper was accomplished from the identification of the problem of high generation of coffee waste and greenhouse gas emissions by the steel industry. By analyzing the national energy system emissions, it was observed that the steel industry segment has an important role due to the high consumption of charcoal and coke in the energy balance. The project aimed to use two biomasses, coffee husk and charcoal as a source of energy in the iron ore reduction process through fine injection sprayed by tuyeres of blast furnaces. The coffee and eucalyptus plant are renewable, unlike coal, and through photosynthesis capture the $\mathrm{CO} 2$ gas from the atmosphere, reducing of the pollution caused by the blast furnace to coke. To simulate the possibility of injecting the biomasses studied, an injection simulator pulverized material was used. We used also techniques to characterize the materials as size, combustion calorimetry gas analysis, specific surface, microscopic and chemical classification. Through the study, this research shows that coffee husk can be injected into blast furnaces partially replacing charcoal.

Keywords: Blast furnace; Injection; Coffee husk; Charcoal.

1 Graduado em Engenharia Metalúrgica - UFOP, Aluno de mestrado em Engenharia de Materiais REDEMAT/UFOP, Ouro Preto, MG, Brasil.

2 Professor do DMQ, CEFET-MG, Timóteo, MG, Brasil.

3 Professor Doutor Titular na REDEMAT e UFOP - Escola de Minas. Pesquisador do CNPq. Conselheiro da EcoEnviroX, Ouro Preto, MG, Brasil.

4 Graduada em Engenharia Metalúrgica - UFOP, Aluna de mestrado em Engenharia de Materiais REDEMAT/UFOP, Ouro Preto, MG, Brasil. 


\section{INTRODUÇÃO}

Dentre as medidas adotadas para reduzir o consumo de energia destaca a injeção de carvão pulverizado $(\mathrm{PCl})$ em altos-fornos, que têm como objetivo reduzir o consumo de coque ou carvão vegetal, além de auxiliar no aumento da produtividade e redução de custos de produção. A injeção de carvão pulverizado é uma realidade e pode ser encontrada em alguns setores taxas de injeção da ordem de até $220 \mathrm{~kg} / \mathrm{t}$ de gusa ${ }^{[1]}$.

Este trabalho teve como objetivo estudar a inserção de outra fonte de energia para a injeção nas ventaneiras de altos-fornos, como as misturas de biomassa de casca de café e carvão vegetal.

O Brasil é o maior produtor de café no mundo, e segundo maior consumidor do mesmo, apresentando uma área de aproximadamente 2,25 milhões de hectares plantados. A sua cultura está presente em 15 estados brasileiros, predominantemente, nos estados de Minas Gerais, Espírito Santo, São Paulo, Bahia, Rondônia, Paraná e Goiás, os quais representam cerca de $98,65 \%$ da produção nacional. O café é o produto agrícola de maior produção e exportação do Brasil. A produção brasileira, em 2015, foi de 43,24 milhões de sacas de café beneficiado (60 kg por saca), totalizando 2,59 milhões de toneladas de café, representando $7 \%$ das exportações do agronegócio brasileiro e gerando uma receita em exportação para o Brasil de 6,16 bilhões de dólares e ocupando a $5^{a}$ posição no ranking. Os principais destinos foram os Estados Unidos, Alemanha, Itália, Japão e Bélgica[2].

No Brasil, a forma mais comum da produção de café ocorre por via seca (fruto de café seco ao sol ou em pré-secadores e secadores artificiais) ${ }^{[3]}$. Desta produção, aproximadamente $50 \%$ do peso colhido são transformados em resíduos sólidos, ou seja, casca de café, o qual constitui um resíduo de baixo custo, renovável, mal aproveitado, ambientalmente correto e potencialmente capaz de gerar calor, vapor e energia[4].

A casca de café é um dos principais resíduos gerados pela produção do café. Logo, o uso deste resíduo no processo de injeção implicaria na redução do consumo de carvão vegetal ou coque, oferecendo uma maior sustentabilidade econômica e ambiental na produção de ferro gusa ${ }^{[5]}$.

\section{MATERIAIS E MÉTODOS}

Neste trabalho estudou-se o comportamento de mistura de carvão vegetal e casca de café pulverizado para injeção em altos-fornos.

Inicialmente as amostras passaram por um ensaio de granulometria com o objetivo de classificar todo material de granulometria entre $0,075 \mathrm{~mm}$ e $0,150 \mathrm{~mm}$. Em seguida as amostras passaram pela estufa a fim de minimizar a umidade do material (menor que $5 \%$ ). As misturas entre carvão vegetal e casca de café são de $25 \%, 50 \%$ e $75 \%$, para uma taxa de injeção de 50 kg/t gusa, $100 \mathrm{~kg} / \mathrm{t}$ gusa e $150 \mathrm{~kg} / \mathrm{t} \mathrm{gusa.}$

As amostras foram submetidas à análise química imediata utilizando adaptações da EN 14774, EN 14775 e EN 15148. A análise química elementar foi levada a cabo usando uma adaptação da norma EN 15104 e EN 15289, o poder calorífico foi analisado usando a norma EN 14918. Foram feitas análises microscópicas das amostras utilizando o Microscópio Eletrônico de Varredura (MEV) do modelo JSM5510 pertencente a UFOP. As amostras também foram submetidas à análise de superfície específica utilizando o analisador BET e, em seguida, foram para o 
Simulador de Injeção de Materiais Pulverizados em Altos-Fornos, ensaio realizado no Laboratório de Siderurgia da Escola de Minas / UFOP. O desenho esquemático do simulador, mostrado na Figura 1, simula as condições de injeção de material pulverizado de ventaneiras de alto-forno, a fim de determinar a taxa de combustão do material em questão.

As simulações são feitas em condições de elevado gradiente térmico $\left(10^{5} \mathrm{~K} / \mathrm{s}\right)$ e baixo tempo de residência da partícula no jato de gás na zona de combustão do altoforno $\left(10^{-2} \mathrm{~s}\right)$, similares ao que ocorre no alto-forno, cujo esquema é mostrado na Figura 1. O Simulador de Injeção de Materiais Pulverizados em Alto-Forno pode ser dividido em 5 seções para um melhor entendimento do aparelho.

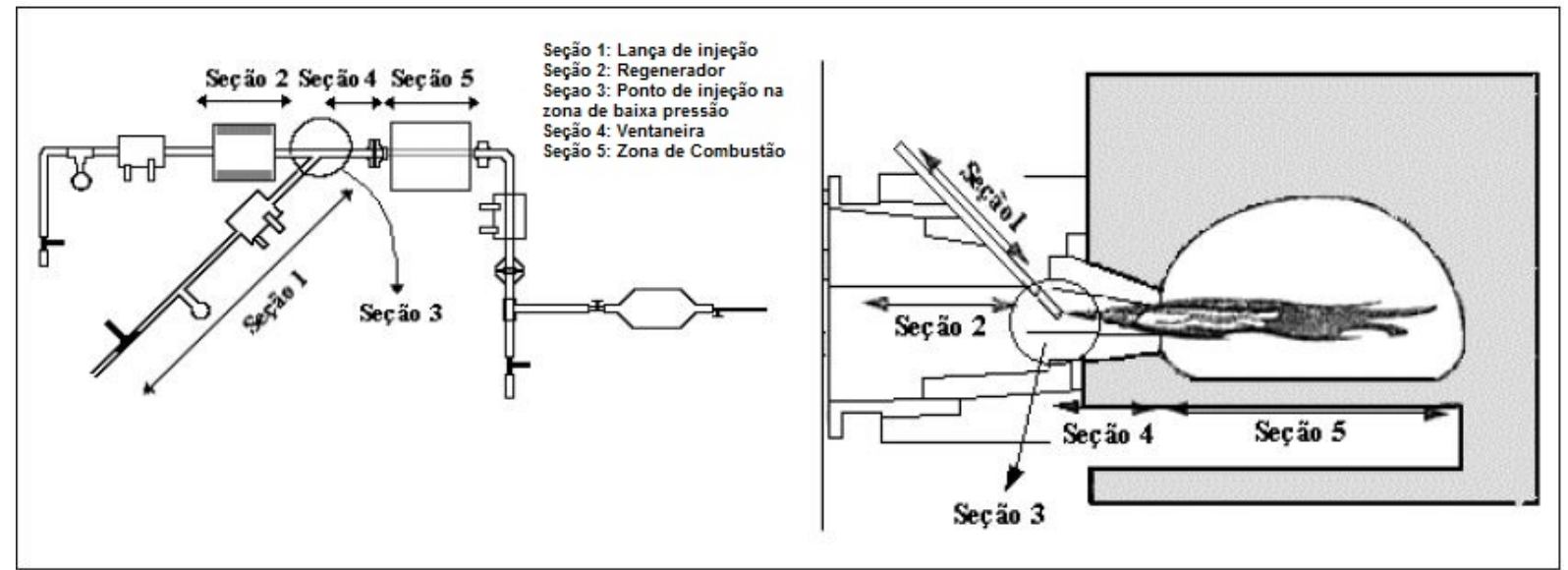

Figura 1. Desenho esquemático das regiões do simulador de injeção de materiais pulverizados em altos-fornos e a similaridade que ocorre no alto-forno ${ }^{[6]}$.

O equipamento utiliza dois fornos, um forno de pré-aquecimento do tipo Kanthal operado com uma variação de temperatura de 0 a $1250^{\circ} \mathrm{C}$. A temperatura do forno é monitorada por um controlador digital de temperatura, ativado por um termopar. A câmara de reação do forno é composta por um tubo de aproximadamente $41,5 \mathrm{~cm}$ de comprimento e $7,5 \mathrm{~cm}$ de diâmetro, sendo esta de aço inoxidável. O objetivo principal deste forno é fornecer calor ao oxigênio (em torno de $1000^{\circ} \mathrm{C}$ ) simulando a temperatura de sopro do alto-forno. O segundo forno simula a zona de combustão capaz de operar a temperaturas acima de $1500{ }^{\circ} \mathrm{C}$, sendo monitorado por um controlador digital de temperatura ativado por um termopar. A finalidade deste forno é simular as características da zona de combustão de um alto-forno.

Próximo à entrada do forno de pré-aquecimento existe um manômetro para ajustar e monitorar a pressão do gás, logo após este, existe um dispositivo de resfriamento operado com água para assegurar que o calor de dentro do forno de préaquecimento não seja conduzido ao gás antes dele chegar ao interior deste. Os dois fornos e a lança de injeção são interligados por tubos de aço inoxidável, sendo que no interior do forno de combustão existe um tubo de quartzo para resistir às altas temperaturas atingidas no interior deste.

A lança de injeção é um tubo de aço inoxidável acoplada aos dois fornos por um ângulo de $32^{\circ}$ como mostra a seção 3, na Figura 1, a uma distância de $15 \mathrm{~cm}$ da entrada do forno de combustão, esta lança consiste de um regulador de precisão para gases que monitora a pressão do gás o qual irá carregar as partículas de material injetado, próximo a este regulador existe uma válvula eletromagnética que impulsiona o gás a ser injetado como acontece em um alto-forno. O material a ser injetado é introduzido no sistema através de uma abertura de $0,4 \mathrm{~cm}$ de diâmetro. 
No fim do tubo do forno de combustão existe um filtro para remover a parte do material que não foi queimado e encaminhar o gás para a válvula eletromagnética a qual emite um pulso que encaminha o gás para ser coletado em uma ampola de vidro e depois segue para posterior análise no analisador de gás ORSAT, Figura 2.

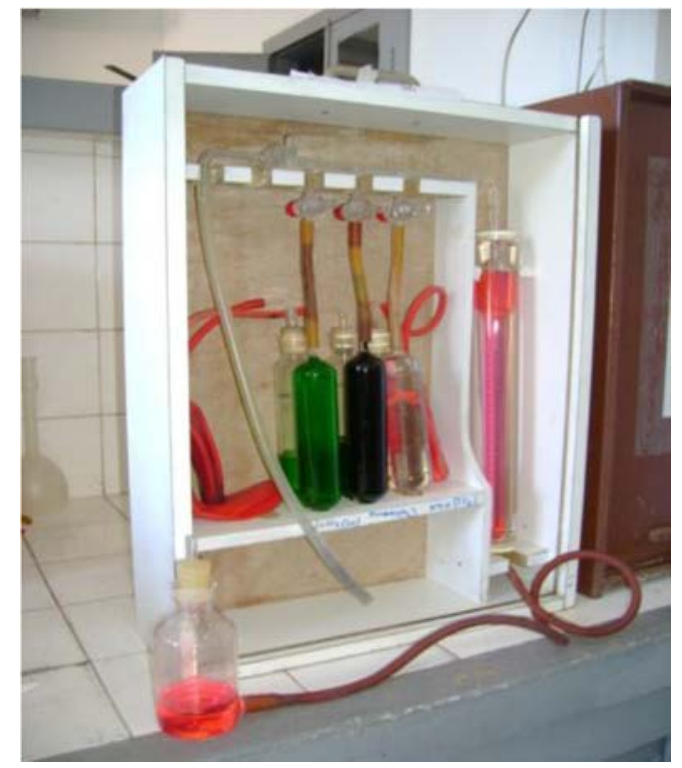

Figura 2. Analisador de gás ORSAT.

O equipamento ORSAT constitui de um conjunto de ampolas de vidro contendo um seu interior soluções necessárias para a análise de gás. Este sistema é interligado por tubos de vidro por onde o gás é forçado a passar, e por adsorção e absorção o gás foi separado em frações, gerando uma leitura no teor de $\mathrm{CO}, \mathrm{CO}_{2}, \mathrm{O}_{2}$ e $\mathrm{CH}_{4}$. As soluções utilizadas são de cloreto de sódio para o metano $\left(\mathrm{CH}_{4}\right)$, hidróxido de potássio para o dióxido de carbono $\left(\mathrm{CO}_{2}\right)$, pirogalol para o oxigênio $\left(\mathrm{O}_{2}\right)$ e cloreto cúprico $\left(\mathrm{CuCl}_{2}\right)$ para o monóxido de carbono (CO).

Foram feitas 5 replicatas para cada mistura de carvão vegetal com casca de café e também para $100 \%$ de carvão vegetal e $100 \%$ de casca de café. Para o procedimento da análise do gás foi utilizado a norma CETESB E17.010[7]. Os resultados das amostras variaram de 0,7 à $1,0 \%$, na qual foram feitas uma média dos valores encontrados para calcular a taxa de combustão.

No processo de análise do gás, a taxa de combustão é expressa por $T_{c}$, Equação 1, calculada em função de uma constante devido as condições do experimento $(\mathrm{K})$, porcentagens dos gases produzidos $\left(\% \mathrm{CO}, \% \mathrm{CO}_{2}, \% \mathrm{CH}_{4}\right)$ e do carbono fixo $\left(\% \mathrm{C}_{\mathrm{f}}\right)$, número de mols do gás depois da experiência $\left(n_{g}\right)$ e da massa da amostra de carbono injetada ( $m_{a}$, em miligramas).

$\mathrm{T}_{\mathrm{c}}=\mathrm{K}^{*}\left(\% \mathrm{CO}+\% \mathrm{CO}_{2}\right){ }^{*} \mathrm{n}_{\mathrm{g}} /\left[\left(\mathrm{m}_{\mathrm{a}}{ }^{*} \% \mathrm{C}_{\mathrm{f}} / 12 \mathrm{12000}\right)-\left(\% \mathrm{CH}_{4}{ }^{*} \mathrm{n}_{\mathrm{g}}\right)\right]$

\section{RESULTADOS E DISCUSSÃO}

Os materiais voláteis são substâncias formadas pelos elementos químicos carbono, hidrogênio e oxigênio. Após a pirólise do carvão liberam gases combustíveis e incombustíveis. Na tabela 1 observa-se que o material volátil da casca de café é 3,27 vezes maior que a do carvão vegetal.

O carbono é um gerador de calor e participa indiretamente da redução da carga metálica. Geralmente quando o teor de carbono aumenta, aumenta a taxa de substituição. E quando o teor de matéria volátil aumenta, aumenta a taxa de 
combustão. As necessidades de enriquecimento em oxigênio para manter a temperatura na zona de combustão diminuem quanto maior for o teor de carbono, porém, para altas taxas de injeção e alto teor de carbono fixo, para que haja altas taxas de combustão, será necessário o enriquecimento do ar com oxigênio, devido a grande diminuição da relação $O / C^{[8,9]}$. Observa-se na tabela 1 que o carbono fixo do carvão vegetal é 5,5 vezes maior que da casca de café e o carbono elementar do carvão vegetal é 1,42 vezes maior que da casca de café.

$O$ hidrogênio é um gerador de calor com menor potencialidade que o carbono. $O$ aumento do teor de hidrogênio dentro do alto-forno reduz a queda de pressão na rampa, a redução do $\mathrm{FeO}$ é menos endotérmica que a do carbono, com maior velocidade e em menor temperatura. Isso implica que pode ser utilizada menor temperatura de chama no alto-forno. Um ponto negativo é que altos teores de hidrogênio podem levar a grande quantidade de finos de coque na cuba do altoforno ${ }^{[8,9]}$. A Tabela 1 mostra que a casca de café possui um pouco mais de hidrogênio que o carvão vegetal.

O aumento do teor de cinzas irá aumentar o volume da escória e aumentar o consumo de calor no alto-forno e, também, leva a um aumento no consumo de carbono, o que reduz a taxa de substituição, aumenta as necessidades de fluxantes e, consequentemente, diminui a produção. Teores de cinza abaixo de $18 \%$ são aceitáveis ${ }^{[9,10]}$. De acordo com a Tabela 1, o carvão vegetal apresenta teor de cinza um pouco acima do aceitável. É importante lembrar que esses materiais podem ser misturados diminuindo o teor de cinza médio injetados no alto-forno, prática esta já usada nas siderúrgicas, com intuito, também, de diminuição de custo.

O enxofre (S) do combustível quando incorporado no ferro-gusa necessitará de dessulfuração posterior, na fabricação do aço. Para diminuir o teor de enxofre no ferro-gusa utiliza-se aumentar o volume da escória e sua basicidade, aumentado o custo de produção do alto-forno. O limite desejável para enxofre é de $0,8 \%$ total nas matérias-primas ${ }^{[9,10]}$. A Tabela 1 apresenta o teor de enxofre do carvão vegetal e da casca de café menor que este limite.

O oxigênio (O) participa da combustão do carbono, hidrogênio e hidrocarbonetos existente no material pulverizado injetado no alto-forno. Sua presença é importantíssima para o aumento da taxa de injeção no alto-forno e diminuição da variação de pressão interna do alto-forno. Desta forma, o oxigênio existente nos materiais reagirá com as substâncias oxidáveis no momento da queima, economizando oxigênio a ser injetado pelas ventaneiras. É importante salientar que isso ocorre quando o oxigênio encontra-se puro $\left(\mathrm{O}_{2}\right)$. Na tabela 1, a casca de café apresenta teor de oxigênio 2,75 vezes maior que o de carvão vegetal.

Geralmente, a taxa de substituição aumenta quanto maior o poder calorífico dos carvões injetados. Carvões com alto poder calorífico aumentam o fluxo de calor na zona de combustão e, consequentemente, a temperatura de chama ${ }^{[10]}$. Através da Tabela 1 verifica-se, também, que o maior poder calorífico superior é do carvão vegetal.

Quanto maior for a área de superfície específica de partícula maior será o contato entre sólidos e gases, ajudando assim a transferência de calor entre o gás-partícula e a cinética de combustão das partículas (reactividade) ${ }^{[5]}$. Para determinada taxa de injecção, aumentando a área de superfície específica de carbono, irá resultar num aumento da taxa de combustão. A área de superfície específica do carvão vegetal é 6,13 vezes maior do que a área de superfície específica da casca de café, mostrando um ponto favorável ao aumento da taxa de combustão. 
Tabela 1. Resultados referentes às análises de poder calorífico, superfície específica, análise química elementar e imediata.

\begin{tabular}{c|c|c|c}
\hline \multicolumn{2}{c|}{ Análises } & Carvão vegetal & Casca de café \\
\hline \multirow{4}{*}{ Elementar } & Carbono [\%] & 61,81 & 43,30 \\
\cline { 2 - 4 } & Hidrogênio [\%] & 2,17 & 5,28 \\
\cline { 2 - 4 } & Oxigênio [\%] & 14,71 & 40,45 \\
\cline { 2 - 4 } & Nitrogênio [\%] & 1,30 & 2,04 \\
\cline { 2 - 4 } Imediata & Enxofre [\%] & 0,11 & 0,24 \\
\hline \multirow{4}{*}{ Poder Calorífico Superior [kcal/kg] } & 19,90 & 8,69 \\
\cline { 2 - 4 } & Cinzas [\%] & 24,80 & 81,28 \\
\cline { 2 - 4 } & Cateriais Voláteis [\%] & 55,20 & 10,03 \\
\hline \multicolumn{2}{c}{ Superfície Específica [m²/g] } & 6236 & 4069 \\
\hline
\end{tabular}

Biomassa apresenta estrutura fibrosa. As fibras são tecidos estruturais das plantas, formadas principalmente por lignina. Visualmente as fibras possuem comprimentos longos e larguras estreitas ${ }^{[11,12]}$. $\mathrm{O}$ carvão vegetal apresenta estrutura lamelar $\mathrm{e}$ porosa, como mostrado na Figura $3^{[1]}$. As fotografias de casca de café, mostrado na Figura 4, mostra claramente a estrutura fibrosa de uma planta.
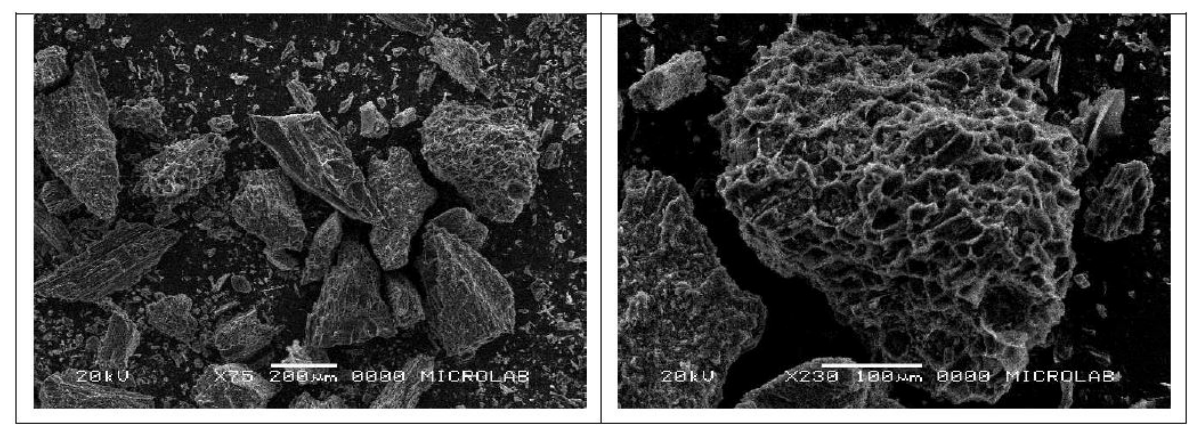

Figura 3. Representação fotográfica de MEV, da amostra de carvão vegetal.

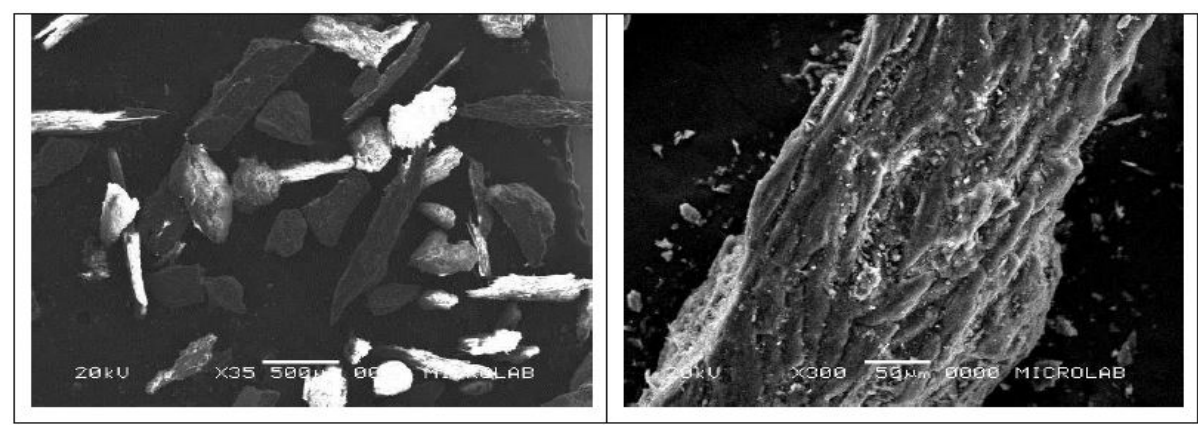

Figura 4. Representação fotográfica de MEV, da amostra de casca de café.

Na Figura 5, observa-se que o aumento da taxa de injeção provoca uma diminuição da taxa de combustão de todos os materiais analisados. Isto é influenciado principalmente pelas condições extremamente severas e do oxigênio presente na zona de combustão. Esses parâmetros influenciam negativamente na eficiência de combustão. Isto pode ser explicado pela menor relação O/C presentes na zona de combustão, portanto gerando uma menor taxa ${ }^{[1]}$. 
Comparando os materiais puros (100\%), carvão vegetal e casca de café, a Figura 5 apresenta taxa de combustão maior para o carvão vegetal, para todos os valores analisados. Isso pode ser explicado pela maior superfície específica do carvão vegetal e maior teor de carbono fixo. A mistura de $50 \%$ de casca de café e $50 \%$ de carvão vegetal apresentou a melhor taxa de combustão para as taxas de injeção estudada. Assim, pode-se dizer que existe uma correlação entre a pirólise e a combustão de materiais voláteis de ambos os materiais.

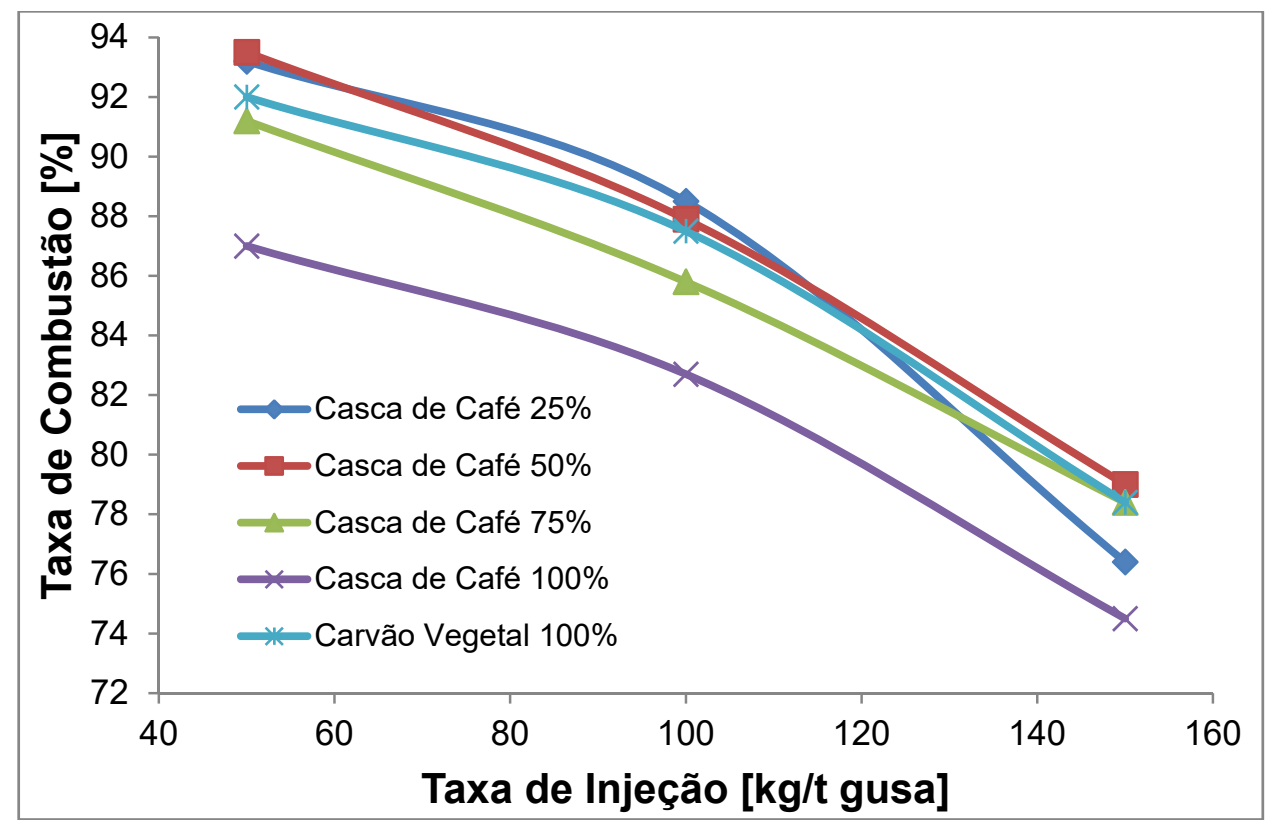

Figura 5. Relação entre taxa de injeção e taxa de combustão, para mistura entre casca de café e carvão vegetal.

Considerando-se especificamente a produção de um alto-forno sem injeção de material pulverizado, para a produção de uma tonelada de ferro gusa, utilizando 500 $\mathrm{kg}$ de coque como carga redutora, são emitidos $1500 \mathrm{~kg}$ de dióxido de carbono $\left(\mathrm{CO}_{2}\right)^{[1]}$.

Para a injeção de $100 \mathrm{~kg}$ de casca de café/t gusa e com a taxa de substituição de $0,7^{[13]}$, retira-se do topo do alto-forno $70 \mathrm{~kg}$ de coque/t gusa. Com isso, reduzindo a carga de coque enfornada pelo topo para $430 \mathrm{~kg}$ de coque/t gusa produzindo 1290 $\mathrm{kg}$ de $\mathrm{CO}_{2} / \mathrm{t}$ gusa, obtendo uma redução de $210 \mathrm{~kg}$ de $\mathrm{CO}_{2} / \mathrm{t}$ gusa do alto-forno.

O pé de café pesa $40 \mathrm{~kg}$ e o café com a casca compõe $7 \%$ deste peso. A casca de café compõe $50 \%$ do peso do café, ou seja, para cada $100 \mathrm{~kg}$ de casca de café são necessários $200 \mathrm{~kg}$ de café em 2,86 t de cafeeiro, o equivalente a 72 pés de cafée ${ }^{[14]}$. Sabendo-se que o cultivo de café no Brasil produz em média 1,63 $t$ de café/hectare/ano na qual são necessários 46,6 t de cafeeiro/hectare/ano, o equivalente a 1165 pés de café/hectare/ano e possui de crédito (ou excedente) 1,53 t CO$_{2} /$ hectare/ano ${ }^{[15]}$, a quantidade absorvida de $\mathrm{CO}_{2}$ pelo cafeeiro para produzir 100 $\mathrm{kg}$ de casca de café é de $93,9 \mathrm{~kg}$ de $\mathrm{CO}_{2} / \mathrm{t}$ gusa.

A diminuição total (injeção + absorção do cafeeiro) de gás $\mathrm{CO}_{2}$ é de $303,9 \mathrm{~kg}$ de $\mathrm{CO}_{2} / \mathrm{t}$ gusa. Uma redução de $20,3 \%$ de emissão de $\mathrm{CO}_{2}$ na atmosfera pelo altoforno.

Utilizando $100 \mathrm{~kg}$ de carvão vegetal/t gusa para injeção e com a taxa de substituição de $1,0^{[16]}$ retira-se do topo do alto-forno $100 \mathrm{~kg}$ de coque/t gusa. Com isso, reduzindo a carga de coque enfornada pelo topo para $400 \mathrm{~kg}$ de coque/t gusa produzindo 1200 $\mathrm{kg}$ de $\mathrm{CO}_{2} / \mathrm{t}$ gusa, obtendo uma redução de $300 \mathrm{~kg}$ de $\mathrm{CO}_{2} / \mathrm{t}$ gusa do alto-forno. 
Considerando um rendimento gravimétrico de produção de carvão vegetal de $19 \%$, a para cada $100 \mathrm{~kg}$ de carvão vegetal são necessários $526 \mathrm{~kg}$ de eucalipto/t de gusa. Sabendo que o cultivo de eucalipto no Brasil produz em média $50 \mathrm{t}$ eucalipto/hectare/ano e possui de crédito (ou excedente) $36,7 \mathrm{t} \mathrm{CO}$ /hectare/ano ${ }^{[17]}$, a quantidade absorvida de $\mathrm{CO}_{2}$ pelo eucalipto para produzir $100 \mathrm{~kg}$ de carvão vegetal é de $386 \mathrm{~kg}$ de $\mathrm{CO}_{2} / \mathrm{t}$ gusa. Porém, para produção de $100 \mathrm{~kg}$ de carvão vegetal são emitidos $122 \mathrm{~kg}$ de $\mathrm{CO}_{2}$, isto considerando um rendimento gravimétrico de $19 \%[18]$

A diminuição total (injeção + absorção pelo cultivo do eucalipto - emissão pela produção do carvão vegetal) de gás $\mathrm{CO}_{2}$ é de $564 \mathrm{~kg}$ de $\mathrm{CO}_{2} / \mathrm{t}$ gusa. Uma redução de $37,6 \%$ de emissão de $\mathrm{CO}_{2}$ na atmosfera pelo alto-forno.

A redução total da emissão de $\mathrm{CO}_{2}$ na atmosfera pelo alto-forno utilizando $100 \mathrm{~kg}$ de casca de café e $100 \mathrm{~kg}$ de carvão vegetal seria de $657,9 \mathrm{~kg} \mathrm{de} \mathrm{CO}_{2} / \mathrm{t}$ gusa, cerca de $43,9 \%$.

\section{CONCLUSÃO}

Em uma avaliação metalúrgica, os resultados analisados mostram que a casca de café pode ser usada na injeção de finos pelas ventaneiras do alto-forno. A taxa de combustão foi melhor para a mistura de $50 \%$ de casca de café e $50 \%$ de carvão vegetal.

No caso ambiental, o café e o eucalipto, através do plantio, podem absorver $\mathrm{CO}_{2}$ da atmosfera pelo processo da fotossíntese. Com isso, reduzindo $43,9 \%$ da emissão de dióxido de carbono $\left(\mathrm{CO}_{2}\right)$ pelo alto-forno e dando um fim rentável ao resíduo da cafeicultura.

\section{Agradecimentos}

Os autores deste artigo gostariam de agradecer ao Departamento de Pesquisa e Desenvolvimento da Usiminas pela análise elementar, a EcoEnviroX por apoiar o desenvolvimento deste estudo, ao CEFET-MG e a UFOP pelo apoio incondicional à inovação. A Fundação Gorceix, FAPEMIG e CNPq pelo apoio financeiro.

\section{REFERÊNCIAS}

1 Assis PS, Martins BM, Vieira CB. Curso de injeção de materiais pulverizados em altosfornos. Belo Horizonte: Associação Brasileira de Metalurgia, Materiais e Minas; 2009.

2 Anuário Estatístico de Café. Ministérios da Agricultura. 2016 [acesso em 28 mar. 2016]. Disponível em: http://www.agricultura.gov.br/vegetal/estatisticas.

3 Vilela FG, Perez JO, Teixeira JC, Reis ST. Uso da Casca de Café Melosa em Diferentes Níveis na Alimentação de Novilhos Confinados. Ciência e Agrotecnologia. 2001; 25(1): 198-205.

4 Vale AT, Gentil LV, Gonçalez JC, Costa AF. Caracterização Energética e Rendimento da Carbonização de Resíduos de Grãos de Café (Coffea Arabica, L.) e de madeira (Cedrelinga Catenaeformis). Cerne. 2007; 13(4): 416-420.

5 Assis CFC. Caracterização de Biomassas para sua Injeção em Alto-Forno. Tese de Doutorado apresentada na Universidade Federal de Ouro Preto, Rede Temática em Engenharia de Materiais. 2014; 1-114.

6 Assis PS, Martins WB, Vieira CB. Avanços na injeção de carvão pulverizado para a sua aplicação em altos-fornos. Revista Escola de Minas. 2003; 56(4): 281-285.

7 Companhia de Tecnologia de Saneamento Ambiental. Aparelho ORSAT para análise de gases de combustão: especificação. São Paulo: CETESB. 1990; 1-7. 
8 Assis PS, Vieira CB, Sobrinho PJN. New developments for Powder Coal Injection into the blast furnaces. Steel Research International. 2004; 4(75): 235-239.

9 Gomes MLI. Avaliação da viabilidade técnica da utilização de misturas de carvão faxinal com importados para injeção em alto-forno. Dissertação de mestrado apresentada na Universidade Federal do Rio Grande do Sul no Programa de Pós-Graduação em Engenharia de Minas, Metalúrgica e de materiais. 2004; 1-111.

10 Oliveira RP, Manetta H, Cruz JG, Maia MES, Gomes DA, Monteiro MR, Costa GB. Operação dos altos-fornos da V\&M do Brasil com altas taxas de injeção de carvão pulverizado. Tecnologia em Metalurgia e Materiais. 2008; 5(2): 105-110.

11 Seye O, Cortez LAB, Gómez EO. Estudo Cinético da Biomassa a Partir de Resultados Termogravimétricos. In: Encontro de Energia no Meio Rural, Campinas. 2003; 3: 1-10.

12 Mello MG. Biomassa: Energia dos Trópicos em Minas Gerais. Belo Horizonte: Editora UFMG; 2001.

13 Ângelo MM. Construção e Simulação de um Algoritmo que Permita Prever os Efeitos da Injeção de diferentes Materiais pulverizados pelas ventaneiras em altos-fornos.

Dissertação de Mestrado apresentada na Universidade Federal de Ouro Preto, Programa de Pós-Graduação em Engenharia de Materiais da Rede Temática em Engenharia de Materiais. 2013; 1-95.

14 Catani RA, Pelegrino D, Bergamin Filho H, Glória NA, Graner CAF. A absorção de nitrogênio, fósforo, potássio, cálcio, magnésio e enxofre pelo cafeeiro. Coffea arábica variedade mundo novo aos dez anos de idade. Escola Superior de Agricultura Luiz de Queiroz. 1965; 22(2): 81-93.

15 Rodrigues VGS, Castilla C, Costa RSC, Palm C. Estoque de Carbono em Sistema Agroflorestal com Café Rondônia - Brasil. In: Simpósio de Pesquisa dos Cafés do Brasil. Agroclimatologia. 2000; 1: 38-41.

16 Fernandes MV. Efeito do Tipo de Carvão Injetado nas Ventaneiras do Alto-Forno no Consumo de Combustíveis (Fuel-Rate). Dissertação de Mestrado apresentada na Universidade Federal de Minas Gerais, Programa de Pós-Graduação em Engenharia Metalúrgica e de Minas. 2007; 1-56.

17 Vergara JDE. Modelagem do Sequestro de Carbono em Plantação de Eucalipto para Fins Energéticos no Cerrado. Dissertação de Mestrado apresentada na Universidade de Brasília, Programa de Pós-Graduação em Engenharia Mecânica e Mecatrônica. 2013; 1-119.

18 Ferreira OC. Emissões de Gases de Efeito Estufa na Produção e no Uso do Carvão Vegetal na Siderurgia. Economia \& Energia. 2000; 20: 1-17. 